ENCYCLOPÉDIE Encyclopédie berbère

BERBERE

$23 \mid 2000$

23 | Hiempsal - Icosium

\title{
Note sur les notices à initiale "I" (/i/)
}

S. Chaker

\section{OpenEdition}

Journals

Édition électronique

URL : http://journals.openedition.org/encyclopedieberbere/1617

DOI : 10.4000/encyclopedieberbere. 1617

ISSN : 2262-7197

\section{Éditeur}

Peeters Publishers

\section{Édition imprimée}

Date de publication : 1 octobre 2000

Pagination : 3563

ISBN : 2-7449-0207-1

ISSN : 1015-7344

\section{Référence électronique}

S. Chaker, "Note sur les notices à initiale "I" (/i/) », Encyclopédie berbère [En ligne], 23 | 2000, document 100, mis en ligne le 01 juin 2011, consulté le 25 septembre 2020. URL : http://journals.openedition.org/ encyclopedieberbere/1617; DOI : https://doi.org/10.4000/encyclopedieberbere.1617

Ce document a été généré automatiquement le 25 septembre 2020

(c) Tous droits réservés 


\section{Note sur les notices à initiale "I" (/} i/)

\section{S. Chaker}

1 Comme l'on sait, de très nombreux mots berbères (des noms communs comme des noms propres) peuvent commencer par un /i/ puisque cette voyelle est la marque initiale régulière du pluriel des noms: ainsi, d'innombrables noms de tribus ou de groupements commencent par un "i" (Igdalen, Isaffen, Igawawen, Iflisen, Iwellemmeden...); on peut aussi rencontrer cette voyelle au singulier, pour des nominaux très fréquents, notamment en toponymie (ifri, "grotte", ighzer, "ravin", ighrem, "citadelle", etc.)- On peut être tenté de ne pas tenir compte de cette voyelle initiale afin de ne pas alourdir la liste des notices en " $i$ ". Un problème identique s'est déjà posé et se posera encore dans l'organisation de l'Encyclopédie berbère pour d'autres séquences initiales particulièrement fréquentes en berbère : $a-$, ayt-, ta-, ti-...

2 Dans tous les cas, l'Encyclopédie berbère, qui entend rester un outil de consultation aisée, immédiatement accessible même au lecteur non-spécialiste des langues de l'Afrique du Nord, maintient la forme courante des mots, telle qu'elle est le plus généralement usitée dans la littérature scientifique de langue française; les notices apparaissent donc sous leur forme usuelle, à la place attendue selon l'ordre alphabétique français.

3 Il en ira de même pour les noms d'origine latine dont le "I" initial est traité en "J" en français (Iuba/Juba, Iugurtha/Jugurtha...) : c'est la forme française courante qui sera toujours retenue et les notices concernées seront donc traitées sous "J". 
INDEX

Mots-clés : Note, Remarque 